\title{
Perioperative anaesthetic management of patients undergoing thoracic cytoreductive surgery and HITHOC
}

\author{
Felipe Unigarro-Londoño ${ }^{1}$, Ricard Navarro-Ripoll ${ }^{1}$, David Sánchez-Lorente ${ }^{2}$, Laureano Molins ${ }^{3}$ \\ ${ }^{1}$ Department of Anesthesiology, Hospital Clinic Barcelona, Barcelona, Spain; ${ }^{2}$ Thoracic Surgeon, Hospital Clinic Barcelona, Barcelona, Spain; \\ ${ }^{3}$ Department of Thoracic Surgery, Hospital Clinic Barcelona, Barcelona, Spain \\ Contributions: (I) Conception and design: All authors; (II) Administrative support: All authors; (III) Provision of study materials or patients: F \\ Unigarro-Londoño, R Navarro-Ripoll; (IV) Collection and assembly of data: F Unigarro-Londoño, R Navarro-Ripoll; (V) Data analysis and \\ interpretation: F Unigarro-Londoño, R Navarro-Ripoll; (VI) Manuscript writing: All authors; (VII) Final approval of manuscript: All authors. \\ Correspondence to: Laureano Molins, MD, PhD. Hospital Clinic, Villarroel 17008036 Barcelona, Spain. Email: LMOLINS@clinic.cat.
}

\begin{abstract}
Historically, patients with pleural malignant mesothelioma have had a poor prognosis and survival rate. Recently, new surgical approaches and chemotherapy delivery techniques have been developed. One of this treatment options is thoracic cytoreductive surgery and HITHOC (hyperthermic intrathoracic chemotherapy perfusion), a promising strategy in selected patients, offering significantly longer median survival length and tumour-free survival rate. However, there is little experience and little is known regarding the optimal perioperative management of this patients. Given that they usually present with poor preoperative status and the surgery is aggressive, prolonged and associated with significant hemodynamic repercussions, this procedure poses a true challenge to the anaesthesiologist. We will discuss optimal patient selection and optimization, as well as premedication, recommended monitoring aspects on top of the usual for any anaesthetic procedure, induction and anaesthetic agents, blood management and one lung ventilation. Also, we expose the importance of adequate pain control during the surgery and postoperatively, the hemodynamic disturbances that occur during the procedure and the potential complications that could occur afterwards. In a few words, this review intends to offer recommendations for the management of patients undergoing cytoreductive surgery and HITHOC for the perioperative care, based on the scarce evidence and our clinical experience.
\end{abstract}

Keywords: Perioperative; hyperthermic intrathoracic chemotherapy perfusion (HITHOC); anaesthesia

Submitted Sep 01, 2020. Accepted for publication Mar 16, 2021.

doi: $10.21037 /$ atm-20-6221

View this article at: http://dx.doi.org/10.21037/atm-20-6221

\section{Introduction}

Cytoreductive surgery and HITHOC (hyperthermic intrathoracic chemotherapy perfusion) is a promising strategy in pleural malignant mesothelioma in selected patients, offering significantly longer median survival length and tumour-free survival rate (1). In fact, HITHOC has been successfully used in the treatment of thoracic tumours and could help to prolong survival in selected M1a lung cancer patients (2). However, there is little experience and little is known regarding the optimal perioperative management of this patients. Patients usually present a poor preoperative status, the surgery is aggressive, prolonged and associated to significant hemodynamic repercussions, and monitoring may not be entirely accurate in this setting. Therefore, this procedure poses a true challenge to the anaesthesiologist. This review intends to offer recommendations for the perioperative anaesthetic management of patients undergoing cytoreductive surgery and HITHOC, based on the scarce evidence and clinical experience. 
Table 1 Potential interventions to optimize preoperative status of patients with malignant pleural mesothelioma proposed for cytoreductive surgery and HITHOC

\begin{tabular}{ll}
\hline Type of intervention & Recommended action \\
\hline Nutritional support & $\begin{array}{l}\text { Malnourishment is common as patients usually present weight loss and decreased oral intake and this may } \\
\text { have prognostic implications (5). Nutritionist advice and protein supplementation may be useful, especially } \\
\text { when combined with exercise training }\end{array}$ \\
$\begin{array}{l}\text { Smoking and alcohol } \\
\text { cessation }\end{array}$ & $\begin{array}{l}\text { Patients should be encouraged to stop smoking and to decrease alcohol intake to avoid postoperative } \\
\text { pulmonary complications }\end{array}$ \\
$\begin{array}{l}\text { Psychological support } \\
\text { Haemoglobin optimisation }\end{array}$ & $\begin{array}{l}\text { Patients usually present some degree of anaemia. Treatable conditions such as iron deficiency should be } \\
\text { investigated }\end{array}$ \\
Exercise training & $\begin{array}{l}\text { There is no evidence regarding exercise programs in this population (6), but it may be a promising tool to } \\
\text { avoid further deterioration and to improve quality of life (7) }\end{array}$ \\
\hline
\end{tabular}

\section{Patient selection, optimization strategies and prehabilitation}

Patient selection is vital to ensure that the combined treatment offers significant benefit to the patients. Participation of the surgical team in the oncologic committees may facilitate early detection of candidates. Furthermore, patients usually receive neo-adjuvant chemotherapy regimens, which gives a precious time to optimize preoperative patients' status. Apart from conventional pre-anaesthetic assessment, including complete physical examination, preoperative cardiac and pulmonary assessment and optimization of previous medical conditions, some interventions may be effective to avoid further deterioration and improve functional capacity. Preoperative optimization strategies such as prehabilitation or pulmonary rehabilitation are promising and might be a useful tool. Prehabilitation is defined as the process of enhancing an individual's functional capacity to enable him or her to withstand a forthcoming stressor, e.g., major surgery (3).

Preoperative exercise-based intervention (prehabilitation) has demonstrated reduction of morbi-mortality in other surgeries but evidence is controversial in thoracic surgery (4). Little is known of which preoperative interventions may be effective to reduce the impact of surgery and to decrease postoperative complications in this specific population. Even if consistent evidence is lacking, it is the author's belief that when gathered together, multiple actions may be beneficial. Some of them are summarised in Table 1.

Even though chemotherapy is administered locally, there is a small risk of renal toxicity in the rare case of systemic effects. In our center, the night before surgery we administer $500 \mathrm{cc}$ of saline $0.9 \%$ to make sure that the fluid status of the patient is adequate.

Preoperative dehydration due to significant effusion, decreased intake or neo-adjuvant chemotherapy toxicity should be solved before surgery. Preoperative dehydration could worsen hemodynamic disturbances during surgery and could help to increase the risk of renal failure. Ideally, basal creatinine level before mesothelioma diagnosis should be aimed in the preoperative period. Increase in preoperative creatinine levels could reflect toxicity or dehydration and should be optimized before surgery.

\section{Intraoperative management}

Due to the relatively low frequency of this surgery, anaesthetic experience is limited. Searching through the current available evidence, it is not entirely clear what is the optimal management for these patients.

\section{Premedication}

Complete preoperative counselling including written and oral information and psychological support may help to decrease preoperative anxiety. Routine administration of sedatives has been recently discouraged in the context of ERAS (enhanced recovery after surgery) in thoracic surgery in order to hasten postoperative recovery (8). Even if considering cytoreductive surgery and HITHOC a different scenario, patients should ideally be extubated at the end of 


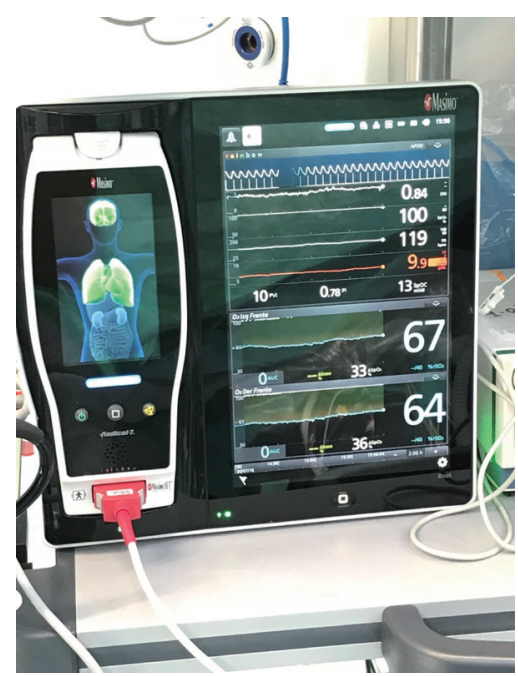

Figure 1 Continuous haemoglobin and cerebral near-infrared spectroscopy monitoring.

the procedure as well. Premedication should be probably reserved for those patients with elevated anxiety levels despite appropriate counselling and psychological support.

\section{Monitoring}

Important and sudden hemodynamic shifts are frequent during the surgery. Wide monitoring may help to early detect changes in fluid status and tissue perfusion. No single monitor is ideal and decision-making is usually based on multiple data and surgical course. There is conflicting evidence regarding goal directed-therapy in thoracic surgery (9) but hemodynamic monitoring is helpful to make the differential diagnosis between hypovolemia, vasodilatation and pericardial obstruction, all of them frequent in this surgery.

Apart from the standard monitoring including ECG, pulse-oximetry, TOF, invasive blood pressure measurement, it is desirable to monitor:

* Temperature: Both oesophageal and nasopharyngeal temperature are monitored. Nasopharyngeal temperature may be the most accurate core temperature source; oesophageal temperature reflects intra-thoracic temperature that may be different from core temperature due to artefacts such as mediastinal irrigation and hyperthermic perfusion.

* Neurological monitoring: at our institution we use BIS ${ }^{\mathrm{TM}}$ for depth of anaesthesia and for cerebral oximetry (NIRS, near infra-red regional saturation) the Massimo O3 Regional Oximetry ${ }^{\mathrm{TM}}$. Regional cerebral oximetry is helpful to determine perfusion changes and helps to assess tolerance to hemodynamic changes and it can also be used as a value to be considered when titrating blood transfusion (see Figure 1).

* Hemodynamic monitoring: central venous pressure is helpful as a marker of mediastinal pressure during intrathoracic chemotherapy perfusion but it has a poor correlation with preload. Non-invasive cardiac output monitoring such as LIDCO $^{\mathrm{TM}}$ rapid system or $\mathrm{PiCCO}^{\mathrm{TM}}$ is useful to assess fluid status, fluid responsiveness and titration of vasoactive drugs.

* Continuous haemoglobin monitoring: even if it doesn't completely replace the need of blood gas sampling during the surgery, it allows continuous monitoring of haemoglobin (10). Some bias is usually found but the trend is really useful to detect unnoticed drops of haemoglobin level during surgery (see Figure 1).

\section{Induction/anaesthetic agents (11)}

There is no evidence of superiority of any anaesthetic agent and the choice between intravenous and inhalational anaesthesia remains unsolved. There are a few characteristics of each option, total intravenous anaesthesia (TIVA) and inhalation agents; that are important especially during onelung ventilation (OLV).

Using data from animal studies, inhalation agents have been linked to a direct inhibition of hypoxic pulmonary vasoconstriction (HPV), which might be detrimental to patient oxygenation levels during OLV, an effect that is not present with intravenous drugs. Many clinical trials have been performed trying to elucidate which type of anaesthesia provides better results during one-lung ventilation; unfortunately, the results are inconsistent. While some of them show an improvement on oxygenation, others fail to do so.

In regards to the inflammatory response to OLV, the evidence is conflictive. While some investigators find lower levels of cytokines in volatile anaesthesia (12), others find lower cytokine concentration with TIVA (13). Given the mixed results, right now there is not enough evidence to recommend one over the other. Some trials are being performed at the moment focusing on the clinical 
importance of the increased concentration of inflammatory mediators.

For TIVA, several agents can be used in combination to provide an effective anaesthesia, including:

* Propofol: most used drug for TIVA. Many advantages, including reduced coughing during emergence from anaesthesia and less depression in bronchial mucus transport velocity.

* Dexmedetomidine: alpha-2 agonist with sedativeanalgesic properties. Benefits include reduced perioperative oxygen consumption and sympathetic response to stimulus and decrease on opioids requirements with better pain control.

* Remifentanil: ultrashort-acting potent opioid. Rapid onset (around $1 \mathrm{~min}$ ) and short duration of action (3$10 \mathrm{~min}$ ). Ideal to manage intraoperative fluctuations of pain but with no residual analgesic effect.

- Ketamine: NMDA receptor antagonist, if used as a sole agent produces a dissociative state, in which sensory output fails to reach consciousness. Useful for thoracic surgery as an adjutant (lower doses) because it produces bronchodilation, reduces narcotic requirement and postoperative pain.

* Lidocaine: multifactorial action, decreases anaesthetic requirements, postoperative analgesic requirements, faster return of bowel function and decreases length of stay.

The choice would depend on the patients' characteristics and personal preferences, aiming at early extubation. In our institution, we use a Propofol-Remifentanil TCI infusion combined with ketamine infusion for pain control.

For neuromuscular blockage, short to intermediate duration agents are recommended. This includes rocuronium, vecuronium, atracurium or cisatracurium. Reversal is mandatory if TOF $<90 \%$.

Antiemetic agents should be used in all patients to prevent postoperative nausea and vomiting (PONV) according to individual risk.

\section{Pain control}

Adequate control of acute pain is mandatory to reduce perioperative complications, morbidity, hospital costs and length of stay. It is important to remember that thoracotomies are linked to a high incidence of chronic postoperative pain (up to $50 \%$ after 5 years) (14) and the risk increases if the acute phase is not controlled, so it is necessary to provide a multimodal approach in order to improve patient comfort and limit the possibility of chronification.

There are many pathways involved. The intercostal nerves are paramount in conducting pain from skin, muscles and rib spread. Also, they play a major role in chronic pain secondary to nerve injury due to the surgery. Then, the vagus and phrenic nerves are responsible for pleuritic pain. For the typical shoulder pain referred by thoracotomy patients, there is no clear pathway described.

Commonly used regional anesthesia/analgesia options for thoracic surgery are either epidural or paravertebral catheter insertion. The aim of these approaches is to provide analgesia that allows the patient to take deep breaths and cough without restriction. For extended pleurectomy/ decortication, continuous paravertebral infusion is not an option since the paravertebral space is bounded anterolaterally by the parietal pleura, which is removed (15).

Epidural catheter insertion is usually performed on an awake patient for safety in case of potential neurological damage (lancinating pain). The most used approach is the loss of resistance technique, in the midline or paramedian. Ultrasound (US) guided puncture is possible but it is difficult and time consuming, with a steep learning curve. The spread of the local anaesthetic depends on age, volume used and site of injection. Higher thoracic have minimal cranial spread but marked caudal spread; lower thoracic levels have predominantly cranial spread. Side effects and complications include sympathetic block, epidural hematoma or abscess, respiratory depression, among others. It is important to remember that the failure rate is about $11 \%$ (14).

In our hospital, as soon as the surgery begins, we start an infusion of ropivacaine $0.16 \%$ + fentanyl $2 \mu \mathrm{g} / \mathrm{mL}$ at a rate between $4-6 \mathrm{~mL} / \mathrm{h}$, maintained for 4 days. As coadjutant medication, we use paracetamol $1 \mathrm{~g}$ TDS, a continuous infusion of intraoperative ketamine $(0.5 \mathrm{mg} / \mathrm{gg} / \mathrm{h})$, which is switched to tramadol $(150 \mathrm{mg} / 24 \mathrm{~h})$ and metamizole $(6 \mathrm{~g} / 24 \mathrm{~h})$ after the surgery, maintained for 3 days postoperative.

This approach can be modified according to institutional preferences and experience. It is recommended to use agents that act on different pathways of pain.

\section{Blood management/transfusion}

Bleeding is common on radical pleurectomy and decortication surgery, with a reported estimated blood loss of 1.5-6.5 L (mean 3.5 L) (15). Strategies to minimize it should be used, including tranexamic acid infusion. There 
Table 2 ROTEM parameters

\begin{tabular}{ll}
\hline Parameter & What it measures \\
\hline CT (clotting time) & Time from adding the start reagent to blood until the clot starts to form \\
CFT (clot formation time) & Time that it takes to reach a $20 \mathrm{~mm}$ clot firmness from CT \\
Alpha angle & Angle of tangent between $0 \mathrm{~mm}$ and the curve when the clot firmness reaches $20 \mathrm{~mm}$ \\
MCF (maximum clot firmness) & Greatest vertical amplitude of the trace \\
A5-10-15-20 & Amplitude of the trace obtained 5, 10,15 or 20 minutes after CFT. Predictor of expected MCF \\
LI 30 & Lysis index after 30 minutes. Detects hyperfibrinolysis \\
\hline
\end{tabular}

is no evidence of its use in this particular surgery, but extrapolating from cardiac or orthopaedics, it is clear that decreases the transfusion rate (16). The optimal dose it's not known, but it is recommended to use a low-dose regimen (defined as $<50 \mathrm{mg} / \mathrm{kg}$ for bolus injection and $\leq 10 \mathrm{mg} / \mathrm{kg}$ $+1 \mathrm{mg} / \mathrm{kg} / \mathrm{h}$ for bolus plus continuous infusion) to avoid deleterious effects, specially seizures (17).

Cell savage devices are not recommended since is relatively contraindicated in malignancy. Packed red blood cells (PRBC) cross-matched for the patient should be available before starting, quantity according to preoperative haemoglobin levels. Other blood products might be necessary, but transfusion should be guided with lab or viscoelastic tests. In our experience (18), we used a mean of 4.5 units of PRBC per patient, fresh frozen plasma and platelets on a case-by-case basis.

POC (point of care) assessment of coagulation has become an important tool for transfusion guidance, mainly because the results are available in 15-20 minutes, compared to 45-60 minutes for routine laboratory tests. ROTEM thromboelastometry is one of the most used alternatives. Thromboelastometry allows detection of hyperfibrinolysis, identification of reduced clot firmness, discrimination between fibrin polymerization disorders and platelet dysfunction, residual heparin effects and deficiency of vitamin-K-dependent factors (19), among others. Measured parameters are described in Table 2. Depending on the reactive and the path of coagulation desired to evaluate, the machine plots a graphic representation of the clot's performance (Figure 2).

Depending of the results, a specific therapy is chosen between the available products in each institution. Although there is not a protocol for POC-based goal directed haemostatic therapy specifically made for thoracic surgery, extrapolation from the large quantity of available ones for cardiac surgery can be useful, tailoring it to hospital and departmental preferences.

\section{One-lung ventilation}

Lung separation is obtained with the introduction of a double-lumen tube. Left sided double-lumen tubes are easier to insert and are often preferred to avoid right superior bronchus obstruction. Protective ventilation during OLV includes the use of PEEP, low-tidal volume ventilation and the use of recruitment manoeuvres (20). This will help to improve gas-exchange during one-lung ventilation and is likely to decrease postoperative pulmonary complications. This may be even more important when considering the prolonged surgical time. There is no difference in outcomes when comparing volume or pressure-controlled ventilation during. There is an on-going debate regarding which is the optimal PEEP level, which is the best recruitment manoeuvres strategy and what does really low-tidal volume means (21). The authors use the open-lung approach to obtain the best pulmonary compliance with lower driving pressure, applying an individualized level PEEP (22).

\section{Hemodynamic disturbances}

The hemodynamic profile depends on the surgical course. During the initial phase there is significant bleeding during the pleuro-decortication and hypovolemia is most frequent. Despite the fact that bleeding is diffuse and hard to minimize with surgical interventions because a wide surgical surface is exposed, exquisite surgical haemostasis is mandatory to avoid further bleeding and hypovolemia during hyperthermic perfusion. Assessment of bleeding is complicated, the gravimetric method (weighing of the pre- and post-procedure gauze) can be useful but timeconsuming (Figure 3).

Fluid losses should be compensated before hyperthermic 


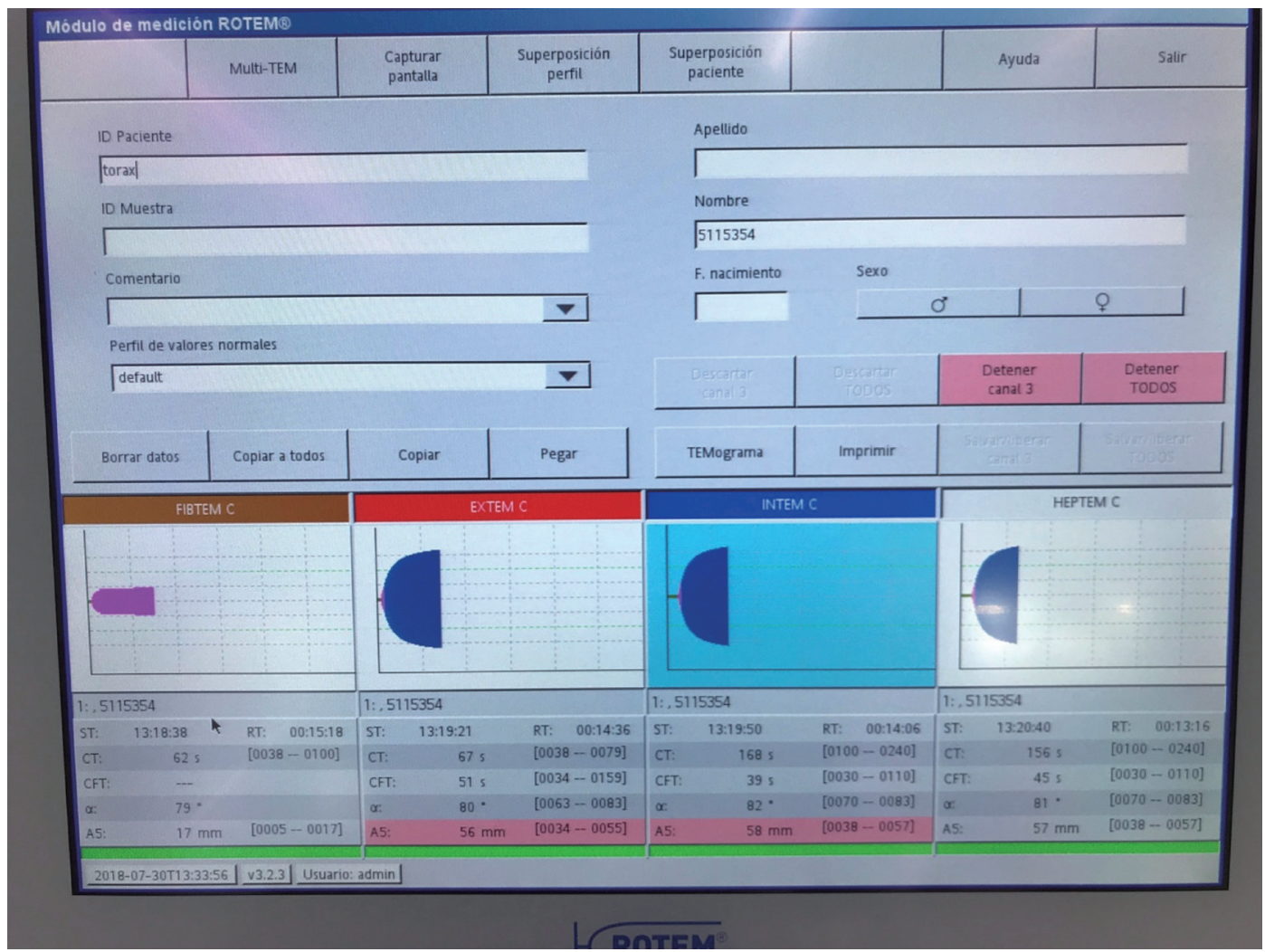

Figure 2 ROTEM analysis during pleurectomy.

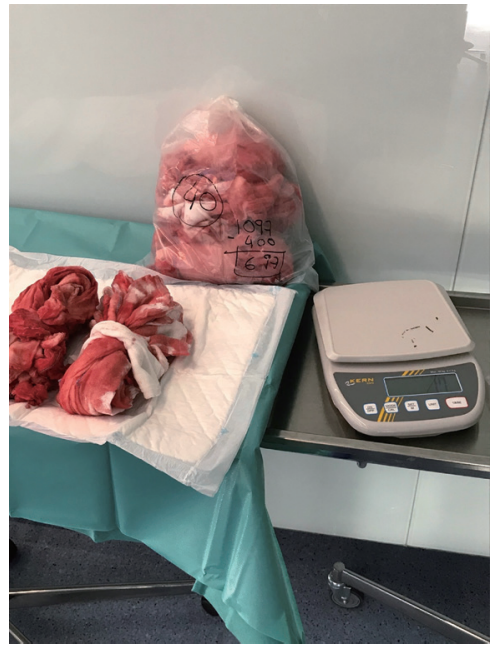

Figure 3 Gauze weight assessment during pleurectomy.

perfusion is established with the aim to avoid profound hemodynamic disturbances (Figures 4 and 5 ).

During hyperthermic perfusion (in our institution: cisplatinum $100 \mathrm{mg} / \mathrm{m}^{2}$ and pemetrexed $300 \mathrm{mg} / \mathrm{m}^{2}$ in $2-3 \mathrm{~L}$ of normal saline depending on chest cavity size and previous lung resection at $41{ }^{\circ} \mathrm{C}$ during 60 minutes), two circumstances may worsen previous hypovolemia. On one side, there is an increase in intra-thoracic pressure during the administration of the chemotherapy that can impair venous return and decrease cardiac preload. At this stage, monitoring central venous pressure is useful because right chambers are more sensitive to compression and acute changes reflect the impact of pleural irrigation. An elevation in central venous pressure is usually observed (Figure 6). On the other hand, hyperthermia and systemic absorption of chemotherapy can induce vasodilatation. According to this, norepinephrine is our first-line vasoactive drug and epinephrine is used as inotropic support if needed. Hemodynamic monitoring including cardiac output, central venous pressure and fluid-responsiveness indices are very useful to assess the hemodynamic profile and vasoactive drug titration.

\section{Postoperative care}

After the surgery, all cases should be transferred to an ICU 

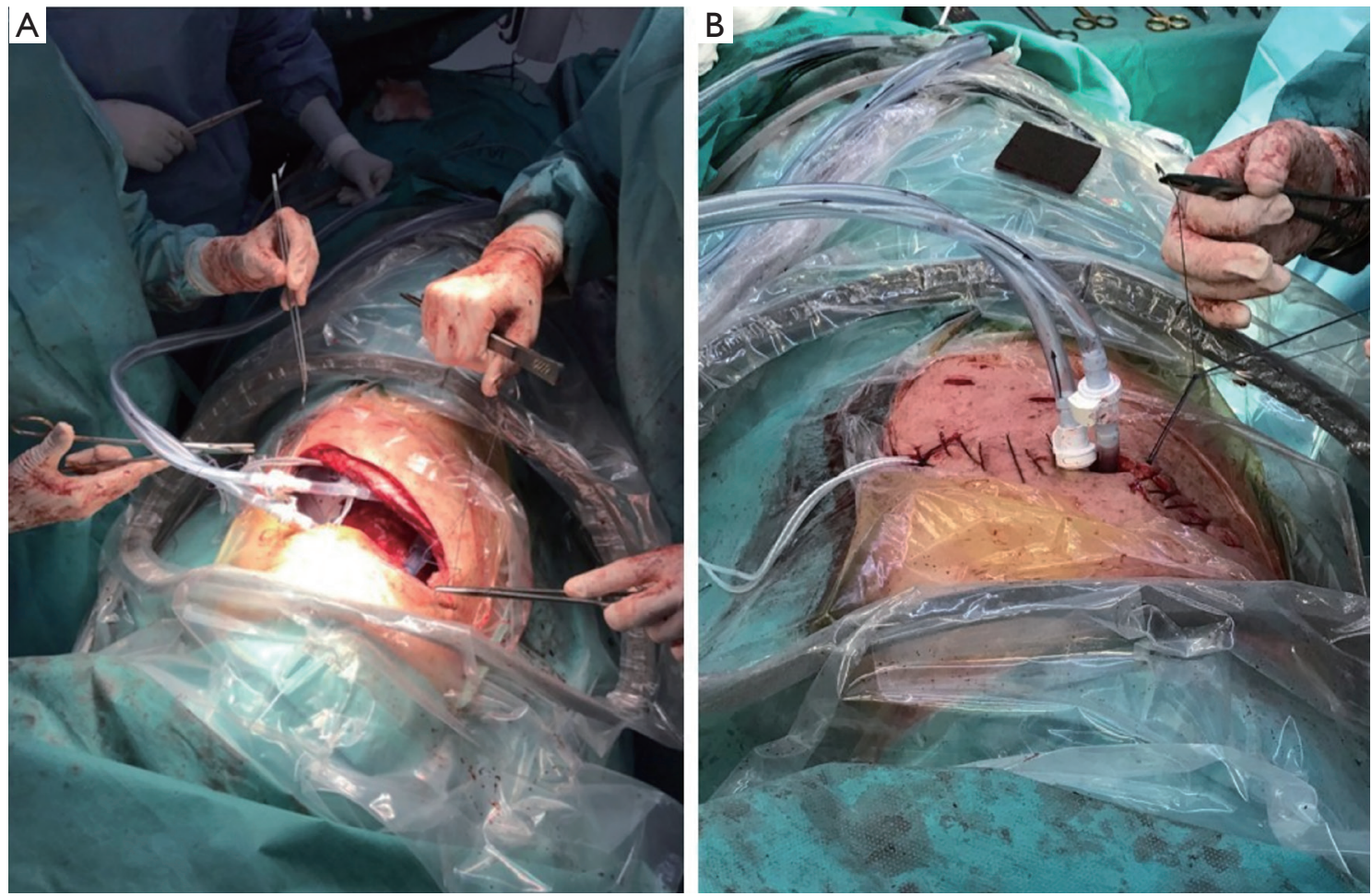

Figure 4 Cannula insertion (A) and chest closure for perfusion (B).
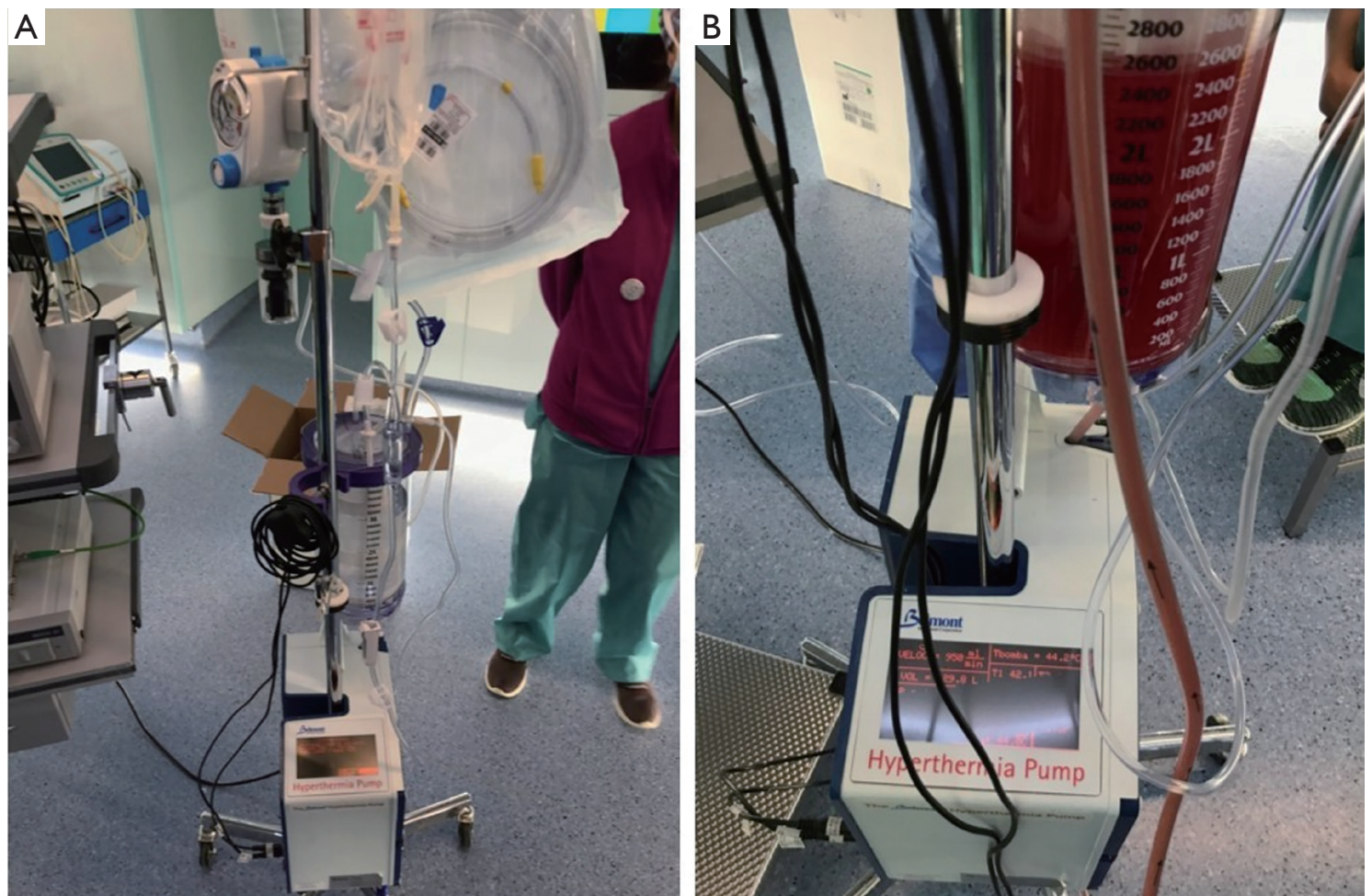

Figure 5 Infusion pump preparation (A) and perfusion during HITHOC (B). 


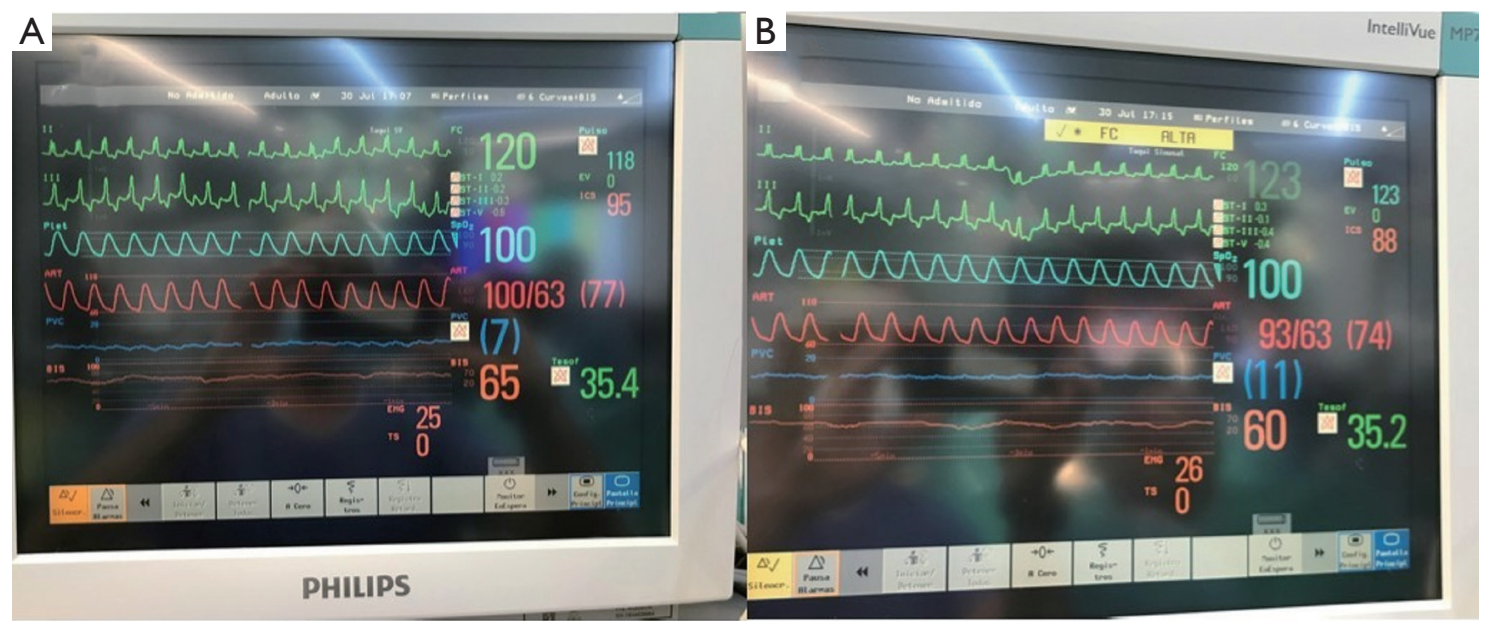

Figure 6 Central venous pressure rise (A, before HITHOC establishment; B, during HITHOC perfusion).

unit due to the intrinsic fragility of the patients, length and duration of surgery. If feasible, they should be extubated in the operating room. Special attention should be given to pain management, respiratory mechanics and venous thrombosis.

Reported complications (23) include atrial fibrillation (24-32\%), thrombosis/embolism (9-13\%), laryngeal nerve dysfunction (11\%), respiratory failure/ARDS (6-11\%) and empyema (15\%). Less common ones include diaphragm rupture, pneumothorax, cytotoxic pleural inflammation, anaemia, air leak.

Renal function should be monitored because of the small risk of renal toxicity from chemotherapy.

Also, in our experience, we have found patients with neutropenia derived from systemic effects of the therapy, luckily in all cases it was self-limited and did not cause any complications.

\section{Acknowledgments}

Funding: None.

\section{Footnote}

Provenance and Peer Review: This article was commissioned by the Guest Editor (Marcello Migliore) for the series "Hyperthermic Intraoperative Chemotherapy (HITHOC) in thoracic surgical oncology" published in Annals of Translational Medicine. The article has undergone external peer review.

Conflicts of Interest: All authors have completed the ICMJE uniform disclosure form (available at http://dx.doi. org/10.21037/atm-20-6221). The series "Hyperthermic Intraoperative Chemotherapy (HITHOC) in thoracic surgical oncology" was commissioned by the editorial office without any funding or sponsorship. The authors have no other conflicts of interest to declare.

Ethical Statement: The authors are accountable for all aspects of the work in ensuring that questions related to the accuracy or integrity of any part of the work are appropriately investigated and resolved.

Open Access Statement: This is an Open Access article distributed in accordance with the Creative Commons Attribution-NonCommercial-NoDerivs 4.0 International License (CC BY-NC-ND 4.0), which permits the noncommercial replication and distribution of the article with the strict proviso that no changes or edits are made and the original work is properly cited (including links to both the formal publication through the relevant DOI and the license). See: https://creativecommons.org/licenses/by-nc-nd/4.0/.

\section{References}

1. Zhou $\mathrm{H}, \mathrm{Wu} \mathrm{W}$, Tang $\mathrm{X}$, et al. Effect of hyperthermic intrathoracic chemotherapy (HITHOC) on the malignant pleural effusion: A systematic review and meta-analysis. Medicine (Baltimore) 2017;96:e5532.

2. Migliore M, Nardini M. Does cytoreduction surgery and hyperthermic intrathoracic chemotherapy prolong survival in patients with $\mathrm{N} 0-\mathrm{N} 1$ nonsmall cell lung 
cancer and malignant pleural effusion? Eur Respir Rev 2019;28:190018.

3. Banugo P, Amoako D. Prehabilitation. BJA Education 2017;17:401-5.

4. Sanchez-Lorente D, Navarro-Ripoll R, Guzman R, et al. Prehabilitation in thoracic surgery. J Thorac Dis 2018;10:S2593-600.

5. Takamori S, Toyokawa G, Taguchi K, et al. The Controlling Nutritional Status Score Is a Significant Independent Predictor of Poor Prognosis in Patients With Malignant Pleural Mesothelioma. Clin Lung Cancer 2017;18:e303-13.

6. van Zandwijk N, Clarke C, Henderson D, et al. Guidelines for the diagnosis and treatment of malignant pleural mesothelioma. J Thorac Dis 2013;5:E254-307.

7. Olivier C, Grosbois J-M, Cortot AB, et al. Real-life feasibility of home-based pulmonary rehabilitation in chemotherapy-treated patients with thoracic cancers: a pilot study. BMC Cancer 2018;18:178.

8. Batchelor TJP, Rasburn NJ, Abdelnour-Berchtold E, et al. Guidelines for enhanced recovery after lung surgery: recommendations of the Enhanced Recovery After Surgery (ERAS®) Society and the European Society of Thoracic Surgeons (ESTS). Eur J Cardiothorac Surg 2019;55:91-115.

9. Zatloukal J, Pouska J, Beneš J. Perioperative goal directed therapy_current view. J Emerg Crit Care Med 2019;3:49.

10. Barker SJ, Shander A, Ramsay MA. Continuous Noninvasive Hemoglobin Monitoring: A Measured Response to a Critical Review. Anesth Analg 2016;122:565-72.

11. Principles and practice of anesthesia for thoracic surgery. 2nd edition. ed. New York, NY: Springer Berlin Heidelberg; 2018.

12. Schilling T, Kozian A, Senturk M, et al. Effects of volatile and intravenous anesthesia on the alveolar and systemic inflammatory response in thoracic surgical patients. Anesthesiology 2011;115:65-74.

13. Hu XL, Tang HH, Zhou ZG, et al. The effect of sevoflurane inhalation anesthesia only and propofol total intravenous anesthesia on perioperative cytokine balance in lung cancer patients. Xi Bao Yu Fen Zi Mian Yi Xue Za

Cite this article as: Unigarro-Londoño F, Navarro-Ripoll R, Sánchez-Lorente D, Molins L. Perioperative anaesthetic management of patients undergoing thoracic cytoreductive surgery and HITHOC. Ann Transl Med 2021;9(11):956. doi: 10.21037/atm-20-6221
Zhi 2011;27:659-61.

14. Yeung JHY, Gates S, Naidu BV, et al. Paravertebral block versus thoracic epidural for patients undergoing thoracotomy. Cochrane Database Syst Rev 2016;2:CD009121.

15. Daunt M, Martin-Ucar AE, Malik M. Malignant pleural mesothelioma and its management. BJA Education 2015;15:242-7.

16. Wong J, El Beheiry H, Rampersaud YR, et al. Tranexamic Acid reduces perioperative blood loss in adult patients having spinal fusion surgery. Anesth Analg 2008;107:1479-86.

17. Guo J, Gao X, Ma Y, et al. Different dose regimes and administration methods of tranexamic acid in cardiac surgery: a meta-analysis of randomized trials. BMC Anesthesiology 2019;19:129.

18. Gómez Tarradas JM, Pujol Fontrodona G, LópezBaamonde M, et al. Manejo anestésico perioperatorio de pacientes con mesotelioma maligno pleural intervenidos mediante cirugía citorreductora y quimioterapia intratorácica. Revista Española de Anestesiología y Reanimación 2020;67:15-9.

19. Görlinger K, Shore-Lesserson L, Dirkmann D, et al. Management of hemorrhage in cardiothoracic surgery. J Cardiothorac Vasc Anesth 2013;27:S20-34.

20. Hu XY, Du B. Lung-protective ventilation during onelung ventilation: known knowns, and known unknowns. J Thorac Dis 2019;11:S237-40.

21. Kidane B, Choi S, Fortin D, et al. Use of lung-protective strategies during one-lung ventilation surgery: a multiinstitutional survey. Ann Transl Med 2018;6:269.

22. Belda J, Ferrando C, Garutti I. The Effects of an OpenLung Approach During One-Lung Ventilation on Postoperative Pulmonary Complications and Driving Pressure: A Descriptive, Multicenter National Study. J Cardiothorac Vasc Anesth 2018;32:2665-72.

23. Zhao ZY, Zhao SS, Ren M, et al. Effect of hyperthermic intrathoracic chemotherapy on the malignant pleural mesothelioma: a systematic review and meta-analysis. Oncotarget 2017;8:100640-7. 